\title{
A Proliferation-Inducing Ligand Regulation in Polymorphonuclear Neutrophils by Panax ginseng
}

\author{
Wioletta Ratajczak-Wrona ${ }^{1}$ (D) Natalia Wawrusiewicz-Kurylonek ${ }^{2}$ (D) Marzena Garley $^{1}{ }^{(1)}$. \\ Adam Jacek Kretowski ${ }^{2,3}$ (D) Ewa Jablonska' ${ }^{1}$
}

Received: 4 January 2020 / Accepted: 25 September 2020 / Published online: 13 October 2020

(c) The Author(s) 2020

\begin{abstract}
A proliferation-inducing ligand (APRIL) is a member of the tumor necrosis factor superfamily that was first identified as a factor favoring tumorigenesis. APRIL is important fitness and survival factors for B cells and plasma cells in the periphery. Considering this, as well as the quantitative predominance of neutrophils among the peripheral blood leukocytes, we carried out the first study assessing the influence of the transforming growth factor (TGF)- $\beta$ signaling pathway on APRIL expression in these cells. Furthermore, as the Rb1 ginsenoside is known to exhibit multiple pharmacological activities, we verified if the saponin is capable of modulating the process. The present study shows that TGF- $\beta$ increased the expression of APRIL and the level of phospho-p38, phospho-Akt(T308), and phospho-Akt(S473) in the cytoplasmic fraction, as well as the expression of Fra1, c-Fos, and c-Jun in the nuclear fraction, of neutrophils. However, exposure of these cells to Rb1 reduced the expression and level of the investigated proteins. No changes were found in the expression of APRIL and the level of p-p38 in the cytoplasmic fraction of neutrophils following the application of $\mathrm{Rb} 1$ alone, as well as in the neutrophils incubated first with Rb1 and then with TGF- $\beta$, whereas a higher level of phosphorylation was observed for Akt and PI3 kinases in the cells. Moreover, a higher expression of all the studied transcription factors was observed in the nuclear fraction of neutrophils. Based on the observed changes, it may be assumed that the expression of APRIL molecule in TGF- $\beta$-induced neutrophils and its regulation by Rb1 are associated with PI3K/AKT signaling pathways and transcription factors Fra-1, Fra-2, c-Jun, and c-Fos. Rb1 appears to be a favorable factor that may be potentially used in the modulation of tumor-promoting APRIL expression.
\end{abstract}

Keywords APRIL $\cdot$ TGF- $\beta$ - Ginsenoside Rb1 $\cdot$ Neutrophils $\cdot$ PI3K/Akt $\cdot$ p38

Wioletta Ratajczak-Wrona

wioletta.ratajczak-wrona@umb.edu.pl

Natalia Wawrusiewicz-Kurylonek

natalia.wawrusiewicz-kurylonek@umb.edu.pl

Marzena Garley

marzena.garley@umb.edu.pl

Adam Jacek Kretowski

adam.kretowski@umb.edu.pl

Ewa Jablonska

ewa.jablonska@umb.edu.pl

1 Department of Immunology, Medical University of Bialystok, J. Waszyngtona 15A, 15-269 Bialystok, Poland

2 Department of Endocrinology, Diabetology and Internal Medicine, Medical University of Bialystok, Bialystok, Poland

3 Clinical Research Centre, Medical University of Bialystok, Bialystok, Poland

\section{Introduction}

Ginseng is the root of Panax ginseng C.A. Meyer (Araliaceae family). It has long been used in Asia, particularly in China, as a therapeutic herb for improving the well-being and alleviating tiredness (Kang and Min 2012). The main bioactive components of ginseng are tetracyclic triterpenoid saponins (ginsenosides), including Rb1, Rg1, Rc, and Rg3 (Chen et al. 2019; Zhuang et al. 2014). They are attributed with properties such as neuroprotectve activity, which can be utilized in the treatment of neurodegenerative diseases (Kang et al. 2019; Li et al. 2019). Animal and cell culture studies have also shown the anticancer and metastatic effects of individual Panax ginseng compounds through their influence on angiogenesis, proliferation, apoptosis, and telomerase activity in cancer cells. Specific anticancer activity is 
attributed to ginsenosides Rg5, Rg3, Rh2, and Rb1 (Kang and Min 2012; Lee et al. 2014; Skopinska-Rozewska 2009).

Ginsenoside Rb1 constitutes the highest amount in ginseng. It was found that this saponin shows estrogenic activity by activating the $\alpha$ and $\beta$ receptors of estrogens (Cho et al. 2004). Rb1 may be transformed into an active metabolite $\mathrm{K}$ as a result of the action of intestinal bacteria (Kang and Min 2012; Park et al. 2005). Metabolite K suppresses the production of PGE2, reduces the synthesis of nitric oxide, and inhibits the expression of NF- $\mathrm{KB}$ in macrophages stimulated with lipopolysaccharide (LPS). At high concentrations, metabolite $\mathrm{K}$, in contrast to $\mathrm{Rb} 1$, increases the level of COX2 (Park et al. 2005). This saponin has also been shown to increase the level of Treg and Th lymphocytes, increase antibody-dependent cytotoxicity, and activate NK cells (Kang and Min 2012; Park et al. 2005). While inhibiting the expression of adhesion molecules, ICAM-1 and VCAM, it reduces the activation and adhesion of monocytes to endothelial cells (Wang et al. 2011). Moreover, ginsenoside Rb1 inhibits apoptosis in damaged nerve cells and cardiomyocytes by increasing the antiapoptotic expression of $\mathrm{Bcl}-2$ protein and decreasing the proapoptotic expression of Bax protein (Guan et al. 2002; Kenarova et al. 1990; Scaglione et al. 1990; See et al. 1997).

The literature data emphasize the important role that ginsenoside $\mathrm{Rb} 1$ plays in the modulation of the immune response, for example, by acting on innate immune cells, including neutrophils (Sun et al. 2007; Youn and Gabrilovich 2013).

Neutrophils are the most abundant circulating leukocytes and are critical effector cells of the innate immune system (Kobayashi 2015; Rosales 2018). Their role in carcinogenesis, however, is still under deliberation. Although polymorphonuclear neutrophils are traditionally considered antitumoral in the context of their anti-bacterial functions, it is becoming increasingly clear that tumor-associated neutrophils (TANs) play a major role in cancer biology (Sionov et al. 2015; Wang et al. 2018). Recent studies suggest that the presence of abundant neutrophils within a tumor is associated with increased tumor growth and hence a poor prognosis (Fridlender and Albelda 2012; Granot and Fridlender 2015; Treffers et al. 2016). Fridlender et al. (2009) characterized TANs into two subcategories of N1 and N2. N1 neutrophils are characterized by high production of pro-inflammatory cytokines and chemokines, an hypersegmented nuclei, low levels of arginase and, in vitro, can eliminate increased numbers of tumor cells. In contrast, N2 subtype have strong immunosuppressive and tumor promoting activity (Andzinski et al. 2015; Coffelt et al. 2016). TANs have been shown to be capable of polarization into either an anti-tumorigenic "N1" phenotype by type-1 interferons or a pro-tumorigenic (N2) phenotype by the presence of transforming growth factor (TGF)- $\beta$ (Shaul et al. 2016).
TGF- $\beta$ is a pleiotropic cytokine, which is produced by numerous cells. It plays a significant role in maintaining tissue homeostasis, among others, by regulating the processes of growth, differentiation, cell migration, formation and degradation of extracellular matrix components, chemotaxis, and apoptosis (Cantelli et al. 2017; Yang et al. 2010). The effect of TGF- $\beta$ in the cancerous process is referred to as the "TGF- $\beta$ paradox" (Tian and Schiemann 2009). TGF- $\beta$ has been demonstrated to act as a cancer suppressor during the early stages of cancer. However, in the advanced stage, it acts as a tumor promoter, contributing to the growth, invasion, and metastases of tumors. Certain cancers most likely develop TGF- $\beta$-inactivating mutations and progress independently of this cytokine. However, others have mutations in cancer suppressor genes that participate in the TGF- $\beta$ signaling pathway (Tian and Schiemann 2009; Yang et al. 2010; Zhang et al. 2014).

The Smad2/3-dependent pathway is assumed to be the key TGF- $\beta$ signaling pathway (Wrana 2019). It conducts the signals from kinase type II receptor (T $\beta \mathrm{R}-\mathrm{II})$, through kinase type I receptor (T $\beta R-I)$, to effector proteins, which then move to the cell nucleus and affect the transcription of target genes (Attisano and Wrana 2002; Cantelli et al. 2017). Amplification of TGF- $\beta$ signaling may also occur via an alternative course ( $\operatorname{Smad} 2 / 3$-independent), involving small GTPases (RhoA, PKN, and Rock), MAP kinases, and PI3 kinase. All these may bind and mediate the Smaddependent signaling or may constitute a completely distinct signaling pathway in different types of cells (Derynck and Zhang 2003; de Caestecker 2004; Keski-Oja et al. 2004; Mehra and Wrana 2002; Miyazawa et al. 2002; Shi and Massague 2003; Zhu and Burgess 2001). Data suggest that this cytokine modulates the synthesis and expression of the proliferation-inducing ligand APRIL in mouse macrophages (Jang et al. 2011).

A proliferation-inducing ligand (APRIL) is a member of the tumor necrosis factor (TNF) family and consists of 250 amino acids encoded by a gene located at chromosome $17 \mathrm{p} 13$. APRIL is produced mostly by cells from the myeloid lineage, including monocytes/macrophages, neutrophils, and eosinophils (Dillon et al. 2006; Vincent et al. 2013a). APRIL signal transduction is mediated by direct binding of the cytokine to at least two cell-surface receptors: transmembrane activator and calcium-modulator and cyclophilin ligand interactor, and B cell maturation antigen (Bat-Erdene et al. 2018; Vincent et al. 2013b; Wollacott et al. 2019). APRIL has antagonistic properties when compared with most of TNF family members. This protein is one of the few that have the ability to stimulate cell growth in different cancer lines (Vincent et al. 2013b).

APRIL is also expressed in cells outside the immune system, including osteoclasts and tumor tissues (Hahne et al. 1998). In cancer patients, a high level of APRIL expression 
indicates a shortened survival time due to the increased aggressiveness of the disease. Studies have shown that APRIL is involved in the induction of signals leading to the proliferation of both leukemia B cells and solid cancer cells (He et al. 2004; Mhawech-Fauceglia et al. 2006). An increased expression of APRIL is observed in Hodgkin's lymphoma, non-Hodgkin's lymphoma, chronic lymphocytic leukemia, and multiple myeloma, as well as in solid intestinal, pancreatic, and breast tumors (Hahne et al. 1998). Data have been reported that cancer cells and hematopoietic cells including infiltrating neutrophils are the source of APRIL in the course of cancer (Mhawech-Fauceglia et al. 2006; Moreaux et al. 2009).

Neutrophils remain in the peripheral blood for approximately $8 \mathrm{~h}$ and then reach the tissues where they survive for up to 3 days (Keshavan et al. 2019; Pillay et al. 2010). Similar to almost all cells found in an organism, neutrophils also possess TGF- $\beta$ receptors (Brandes et al. 1991; Shen et al. 2007). However, only a few studies analyzing the TGF- $\beta$ pathway in neutrophils are available in the literature, and these do not provide any information on the impact of TGF- $\beta$ on APRIL expression (Shen et al. 2007; Travis and Sheppard 2014). Considering this, as well as the quantitative predominance of neutrophils among the peripheral blood leukocytes, we carried out the first study assessing the influence of the TGF- $\beta$ signaling pathway on APRIL expression in these cells. Furthermore, as the Rb1 ginsenoside is known to exhibit multiple pharmacological activities (Xin et al. 2019), we verified if the saponin is capable of modulating the process. Understanding the mechanisms that regulate the expression of APRIL in neutrophils can contribute to analyzing the general mechanisms of signal transduction in these cells.

\section{Materials and Methods}

\section{Neutrophil Isolation}

Neutrophils were obtained from the blood of 15 healthy volunteers (males). All experimental procedures were approved by the Ethics Committee of the Medical University of Bialystok.

Neutrophils were isolated using density-gradient centrifugation with Polymorphprep ${ }^{\mathrm{TM}}$ reagent (AXIS-SHIELD PoC AS, Oslo, Norway). Bürker chamber and Türk's solution were used for counting the cells. Cell purity was assessed by applying the thick drop method, using May-Grünwald and Giemsa dyes. For subsequent isolation, donor cell preparations that exhibited high cell purity with more than $85 \%$ neutrophils were used. To obtain a pure cell fraction, the magnetic MACS ${ }^{\circledR}$ Separator, as well as antibodies and magnetic CD16 MicroBeads (no. catalog no. 130-045-701; Miltenyi
Biotec), was used for positive separation. The viability of neutrophils was assessed in preparations formed directly after isolation, as well as in those incubated for $20 \mathrm{~h}$, using trypan blue dye. Sera were obtained from blood samples collected without anti-coagulation agents.

\section{Neutrophil Incubation}

Neutrophils were resuspended in HBSS (Invitrogen, Carlsbad, CA, USA) medium supplemented with donors' own serum (7.4\%), antibiotics (streptomycin and penicillin) and seeded at $5 \times 10^{5}$ cells/well in sterile plates. Neutrophils were divided into five different groups which were incubated with or without human recombinant TGF- $\beta$ (rhTGF- $\beta$; $10 \mathrm{ng} / \mathrm{ml}$ ) (R\&D Systems) and/or ginsenoside Rb1 (50 $\mu \mathrm{g} /$ ml) (HWIANALITIK GMBH Pharma Solution Ruelzheim, Germany) according to cell culture outline presented on Fig. 1. All cells were preincubated for $30 \mathrm{~min}$ with or without ginsenoside Rb1. Thereafter rhTGF- $\beta$ and/or ginsenoside $\mathrm{Rb} 1$ were added into wells and the plate was incubated for next $20 \mathrm{~h}$ at $37^{\circ} \mathrm{C}$ in $5 \% \mathrm{CO}_{2}$ (Nuaire ${ }^{\mathrm{TM}} \mathrm{US}$ Autoflow, Plymouth, MN, USA).

\section{Gene Expression}

The whole cellular RNA was extracted and purified using the RNeasy Mini Kit (Qiagen, Germany) by the common protocol. The expression of APRIL gene was assessed by two-step quantitative real-time PCR, using ready-touse TaqMan Gene Expression Assays (Hs00601664_g1, NM_003808.3, ThrmoFisher Scientific, USA) and using the 7900HT Fast Real-Time PCR System (Applied Biosystems, USA). cDNA synthesis was performed using High Capacity cDNA Reverse Transcription Kit (Life Technologies, USA) from $1 \mu \mathrm{g}$ of total RNA in the MJ Research Thermal Cycler (Model PTC-200, USA). The 18S rRNA gene was used as a reference gene for normalising qRT-PCR data. The reaction mix consisted of cDNA probes, TaqMan Gene Expression Master Mix (Applied Biosystem, USA) and each TaqMan Gene Expression Assay in the appropriate volume in duplicates. The relative gene expression results were determined by RQ Manager Software (Applied Biosystem, USA).

\section{Immunoblotting}

The collected neutrophils were centrifuged and washed with PBS (Gibco, 10010-015). Cytoplasmic and nuclear protein fractions from these cells were prepared using the NucBuster $^{\mathrm{TM}}$ Protein Extraction Kit (Novagen ${ }^{\circledR}, 71183-3$ ). The protein concentration was detected using a Qubit ${ }^{\mathrm{TM}}$ Protein Assay Kit and Qubit 2.0 Fluorometer (Invitrogen, Q33211).

The immunoblotting confirmed the presence of APRIL, phospho-Akt (T308), phospho-Akt (Ser 473), 


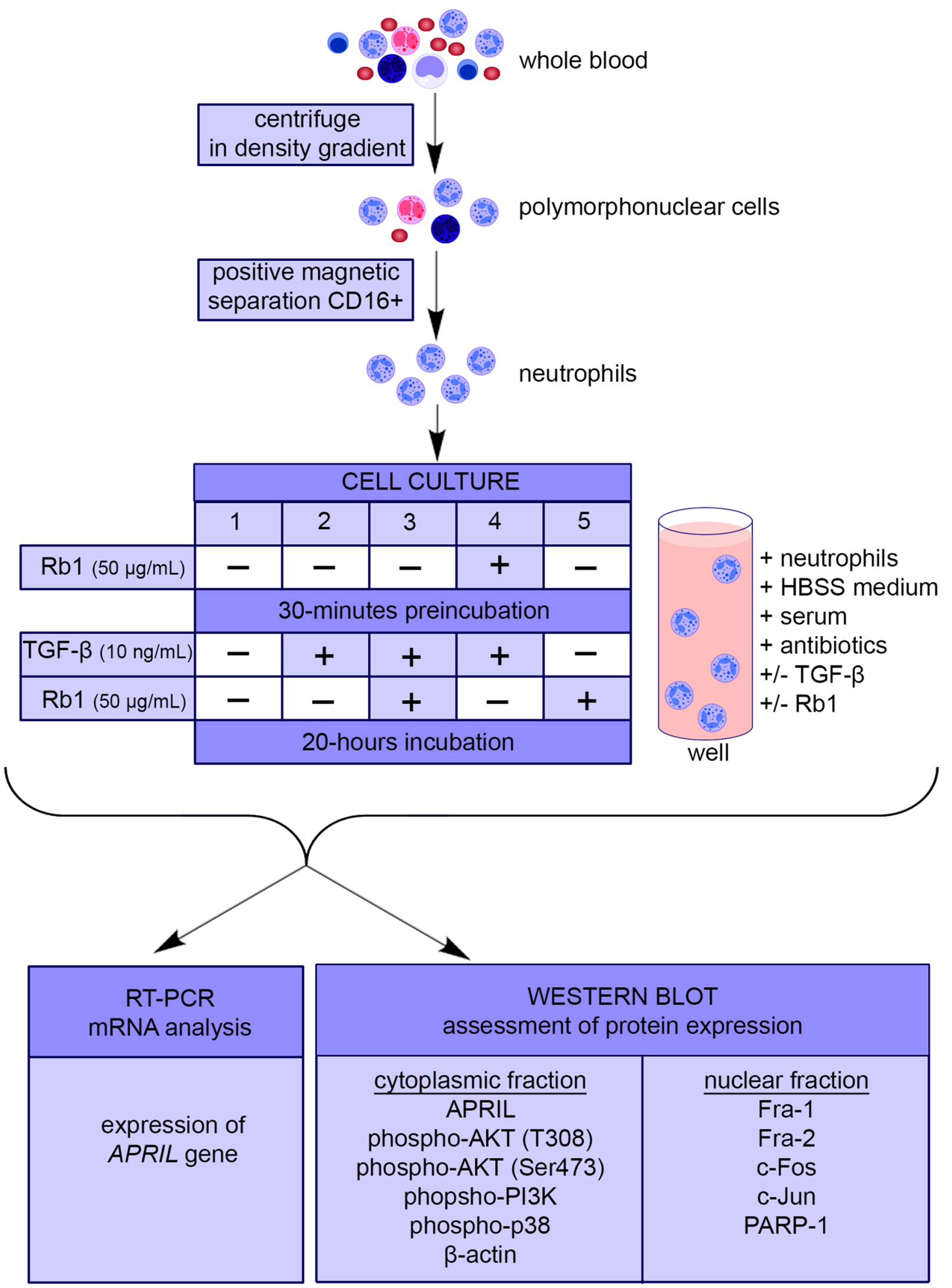

Fig. 1 Research methodology workflow 
phospho-PI3K, phospho-p38, Fra-1, Fra-2, c-Fos and c-Jun proteins. As an internal control the PARP-1 (nuclear protein fractions) and $\beta$-actin (cytoplasmic protein fractions) proteins were used.

Cytoplasmic or nuclear protein fractions were suspended in Laemmli Sample Buffer (Bio-Rad Laboratories, 1610737) with $\beta \mathrm{ME}$ (Bio-Rad Laboratories, 161-0710). Equal amount of proteins was separated by SDS-PAGE and transferred onto nitrocellulose membrane (Bio-Rad Laboratories Mini-PROTEAN® Tetra Cell). Membrane was blocked with 1xTBS 1\% Casein Blocker (Bio-Rad Laboratories, 1610782) in the Millipore SNAP i.d. ${ }^{\text {TM }}$ Protein Detection System during a 20-s incubation and incubated with primary antibodies $10 \mathrm{~min}$ and after that with secondary antibodies $10 \mathrm{~min}$, at room temperature (according to the manufacturer's instructions).

The proteins were immunoblotted with primary antibodies: anti-human APRIL/TNFSF13 Antibody (R\&D Systems, AF884, goat polyclonal; $0.2 \mu \mathrm{g} / \mathrm{ml}$ ), p-Akt1/2/3 (B-5) (SantaCruz Biotechnology, sc-271966, mouse monoclonal; 1:100), p-Akt1/2/3 (Ser473) (SantaCruz Biotechnology, sc-33437, rabbit polyclonal; 1:200), p-PI 3-kinase p85 $\alpha$ (Tyr508) (SantaCruz Biotechnology, sc-12929, goat polyclonal; 1:200), p-p38 (E-1) (SantaCruz Biotechnology, sc-166182, mouse monoclonal; 1:100), Fra-1 (C-12) (SantaCruz Biotechnology, sc-28310, mouse monoclonal; 1:100), Fra-2 (G-5) (SantaCruz Biotechnology, sc-166102, mouse monoclonal; 1:100), cFos (C-10) (SantaCruz Biotechnology, sc-271243, mouse monoclonal; 1:100), c-Jun (G-4) (SantaCruz Biotechnology, 74543, mouse monoclonal; 1:100), PARP-1 (Ab-3) Mouse mAb (F1-23) (Calbiochem, AM68, mouse monoclonal; 1:5000), $\beta$-Actin (9) (SantaCruz Biotechnology, sc-130301; mouse monoclonal; 1:200) followed by the secondary antibodies: Goat Anti-Rabbit IgG-AP (Santa Cruz Biotechnology, sc-2007; 1:5000), Alkaline Phosphatase-conjugated AffiniPure Mouse Anti-Goat IgG (H + L) (Jackson ImmunoResearch Laboratories, 205-055-108; 1:5000) or Alkaline Phosphatase-conjugated AffiniPure Goat Anti-Mouse IgG (H+L) (Jackson ImmunoResearch Laboratories, 115-055-062; 1:5000). Excess unbound antibodies were washed away with TBS-T buffer [10xTBS (Bio-Rad Laboratories, 170-6435) with Tween ${ }^{\circledR}-20$ (Sigma, P9416)]. Detection was performed using the 5-bromo-4-chloro-3-indolylphosphosphate as a substrate, and nitroblue tetrazolium as a chromogenic indicator [BCIP ${ }^{\circledR} /$ NBT Liquid Substrate System (Sigma, B1911)].

The color intensity of the protein bands was evaluated by densitometric analysis using ImageJ software (NIH, Bethesda, MD, USA) and presented in graphs as an arbitrary units.

\section{Statistical Analysis}

The data were treated using the STATISTICA version 13.1 program (StatSoft, Inc., Tulsa, OK, USA). The level of statistical significance was preset to $p<0.05$ (two-tailed). Statistical significance of differences was determined by Student's $t$ test or analysis of variance (ANOVA; Tukey-Kramer's post-hoc test). Mean values are expressed \pm standard error (SE).

\section{Results}

\section{Evaluation of APRIL mRNA Expression by RT-PCR}

The neutrophils stimulated with TGF- $\beta$ showed an increased expression of APRIL compared to the nonstimulated cells. However, the neutrophils incubated first with TGF- $\beta$ and then with Rb1 showed a lower expression of APRIL mRNA compared to the cells stimulated with TGF- $\beta$ only (Fig. 2).

\section{Evaluation of Protein Expression by Immunoblotting}

Analysis of the results demonstrated that the exposure of neutrophils to TGF- $\beta$ increased the expression of APRIL in the cytoplasmic fraction as compared to nonstimulated cells. In addition, these cells showed a higher level of phosphorylation for the following kinases: p38, Akt(T308), and Akt(S473). On the other hand, the phosphorylation of PI3K remained at the same level as in the cells not exposed to TGF- $\beta$ (Fig. 3).

Incubation of neutrophils with TGF- $\beta$ and Rb1 reduced the expression of APRIL, as well as the level of phosphop38, phospho-Akt(T308), and phospho-Akt(S473) in the cytoplasmic fraction, compared to cells stimulated solely with TGF- $\beta$. However, no changes were found in the phospho-PI3K level in the cytoplasmic fraction of these cells (Fig. 3).

In addition, no changes were observed in the expression of APRIL and the level of p-p38 in the neutrophils incubated with $\mathrm{Rb} 1$ alone, as well as in those incubated first with $\mathrm{Rb} 1$ and then with TGF- $\beta$, in comparison with the nonstimulated cells. However, a higher level of phosphorylation of the following kinases was seen in these cells: Akt(T308), Akt(S473), and PI3K. The level of phosphorylation was also higher in these cells in comparison with the cells stimulated solely with TGF- $\beta$ and those incubated first with TGF- $\beta$ and then with Rb1 (Fig. 3).

The neutrophils exposed to TGF- $\beta$ showed a simultaneous increase in the expression of Fra1, c-Fos, and c-Jun in the nuclear fraction compared to the nonstimulated cells. 


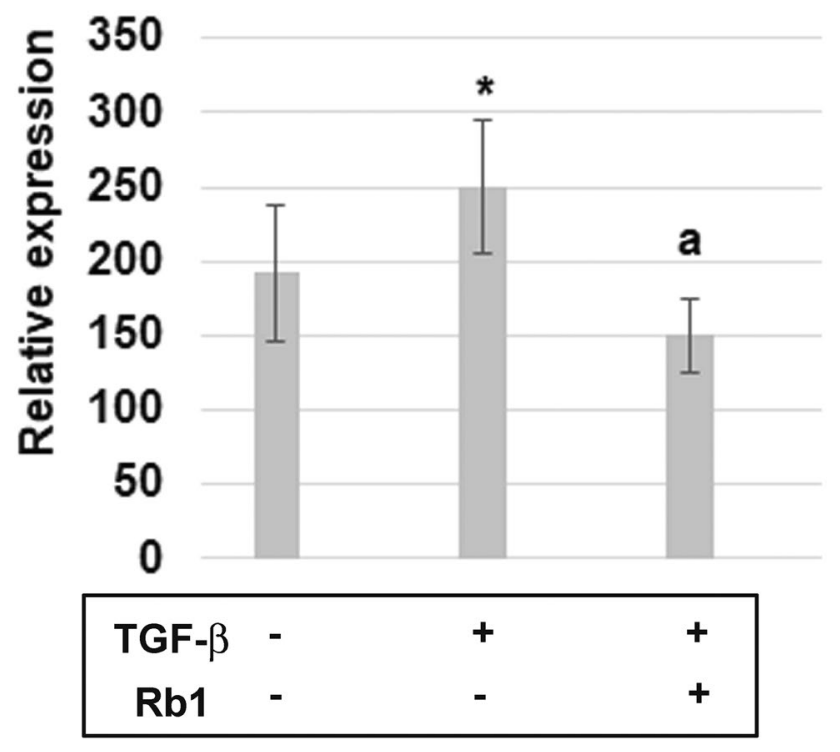

Fig. 2 Expressions of APRIL-mRNA in neutrophils from 15 healthy volunteers. Effect of TGF- $\beta(10 \mathrm{ng} / \mathrm{ml})$ or with $\mathrm{Rb} 1(50 \mu \mathrm{g} / \mathrm{ml})$ on the expression of APRIL-mRNA. RT-PCR was performed on human neutrophils. mRNA of APRIL levels were normalized to house-keeping gene-s18. Value significantly different between * unstimulated and stimulated cells $(\mathrm{p}<0.05)$; a cells incubated only with TGF- $\beta$ and cells incubated with TGF- $\beta$ and Rb1 $(\mathrm{p}<0.05)$

However, a lower expression of Fra2 was observed in these cells (Fig. 4).

The expression of all the studied transcription factors in the nuclear fraction was lower in the neutrophils incubated with TGF- $\beta$ and Rb1 compared to the cells incubated only with TGF- $\beta$. Additionally, the expression of Fra2 and c-Fos in the studied fraction of these cells was lower compared to that observed in the nonstimulated cells (Fig. 4).

The cells stimulated with $\mathrm{Rb} 1$ showed an increased expression of all the studied transcription factors compared to the nonstimulated cells. The expression of Fra2 and c-Fos was also higher in these cells compared to the cells incubated with TGF- $\beta$ (Fig. 4).

The neutrophils incubated first with Rb1 and then with TGF- $\beta$ showed a higher expression of Fral and a lower expression of c-Fos and c-Jun compared to the nonstimulated cells and the cells stimulated only with Rb1. However, no changes in the expression of the transcription factor Fra2 were found in these cells (Fig. 4).

The expression of Fra1, Fra2, and c-Fos proteins in the cells incubated first with Rb1 and then with TGF- $\beta$ was higher compared to the cells stimulated first with TGF- $\beta$ and then with Rb1. However, no changes in the expression of c-Jun were found in these cells (Fig. 4).
Fig. 3 Representative western blots showing the expressions of APRIL, phospho-p38, phospho-PI3K, phospho-Akt(T308) and phospho-Akt(S473) in neutrophils. Neutrophils were treated with TGF- $\beta$ (10 $\mathrm{ng} / \mathrm{ml})$ or with/without Rb1 $(50 \mu \mathrm{g} / \mathrm{ml})$. Cytoplasmic fractions obtained from those cells were used for assessment of APRIL, phospho-p38, phospho-PI3K, phospho-Akt(T308) and phospho-Akt(S473) protein levels via Western blot analyses. Band intensity was quantified using ImageJ software and expressed in arbitrary units (A.U.). Data shown are mean $( \pm$ SE) of five independent experiments. Value significantly different between * unstimulated and stimulated cells ( $\mathrm{p}<0.05)$; a cells incubated only with TGF- $\beta$ and cells incubated with TGF- $\beta$ and Rb1 ( $p<0.05)$; b stimulated cells and incubated only with TGF- $\beta(\mathrm{p}<0.05)$; $\mathbf{c}$ stimulated cells and incubated with TGF- $\beta$ and Rb1 $(\mathrm{p}<0.05)$

\section{Discussion}

To a large extent, the development of cancer is determined by the interaction of cancer cells and cells of the immune system. The effect of their activity is, for example, synthesis and release of cytokines that affect their mutual interactions. The results of many clinical and experimental studies have shown that neutrophils, the cells which constitute the highest percentage among all leukocytes infiltrating the tumor, show a high expression of APRIL in cancer patients (Coffelt et al. 2016; Moreaux et al. 2009).

The results of this study demonstrated for the first time that TGF- $\beta$ induces the activation of APRIL in human neutrophils through its effects. Changes observed in the level of Akt kinase phosphorylation with the lack of changes in the phosphorylation of the PI3 kinase regulatory subunit p85 suggest that the TGF- $\beta$ signaling pathway most likely activates Akt kinase by activating another subunit of the PI3 kinase dimer.

Few reports suggest that in human neutrophils, Akt kinase occurs as a complex with p38, MAPKAPK-2, and Hsp27 proteins, which participates in the phosphorylation of T308 and S473, and thus in the activation of AKT, as well as their autophosphorylation leading to the release of these proteins from the complex (Hanada et al. 2004; Hawkins et al. 2010; Okkenhaug 2013). Therefore, elevated phosphorylation of p38 observed in the neutrophils stimulated with cytokine suggests the involvement of $\mathrm{p} 38$ kinase in the TGF- $\beta$ signaling pathway in these cells.

Research data indicate that the activity of proteins forming the transcription factor AP-1 can be regulated at transcriptional and posttranscriptional levels as well as by the phosphorylation of its components by different MAP kinases. It should be emphasized that although p 38 does not activate the AP-1 proteins directly, this kinase may regulate the transcription of jun and fos by the phosphorylation of ATF-2, ELK-1, SAP-1, and CCAAT factors, with which it binds to the promoter fragment of jun and fos, which leads to the regulation of their transcription (Karin 1995; Reddy and Mossman 2002; Shaulian and Karin 2002). The obtained 


\section{$\beta$-actine}
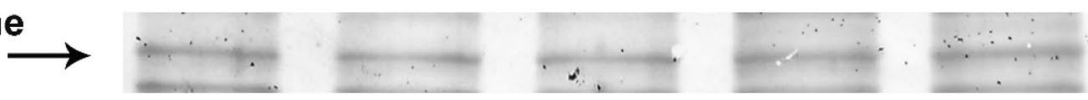

APRIL

(32 kDa)

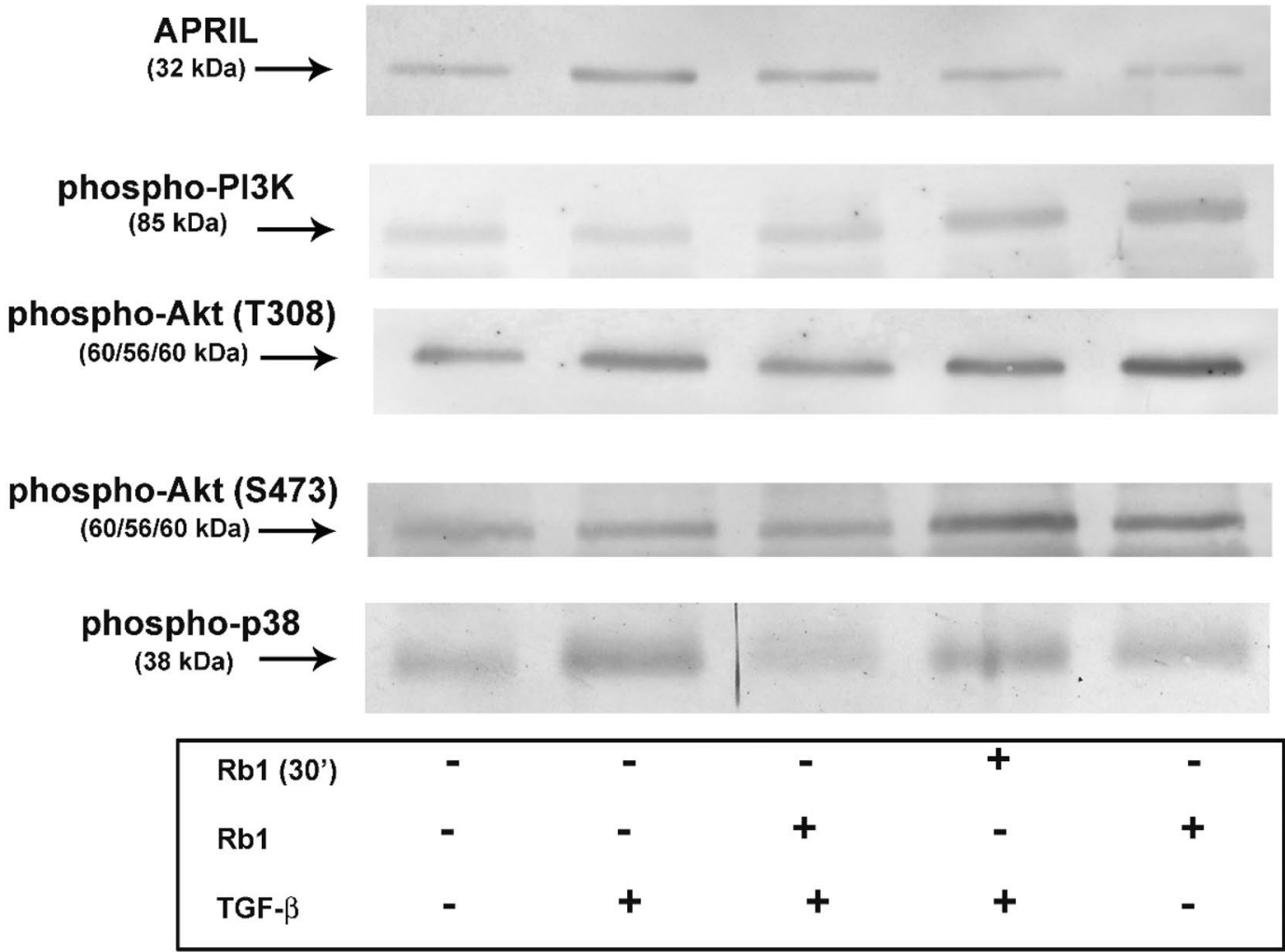

APRIL

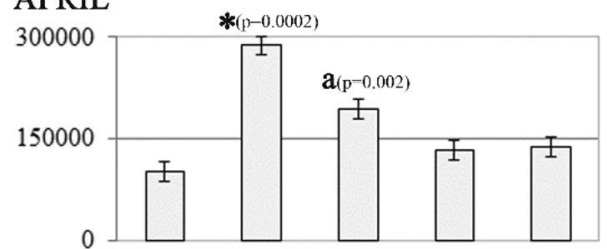

phospho-PI3K

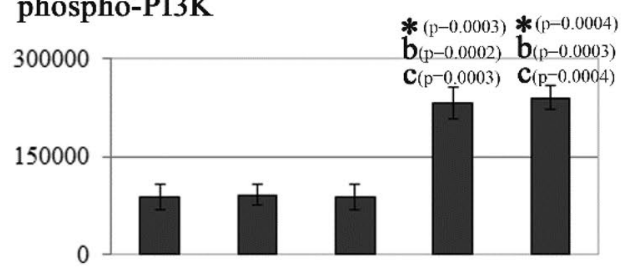

phospho-p38

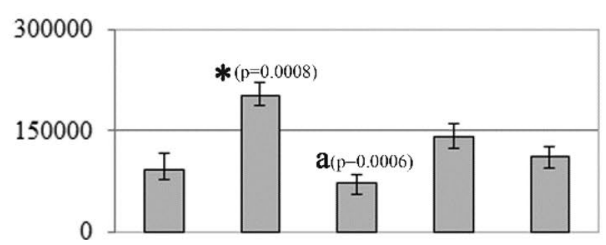

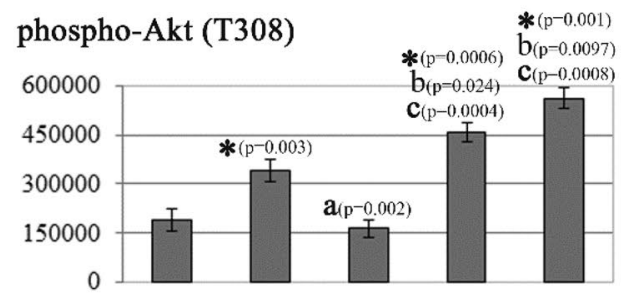

phospho-Akt (Ser473)

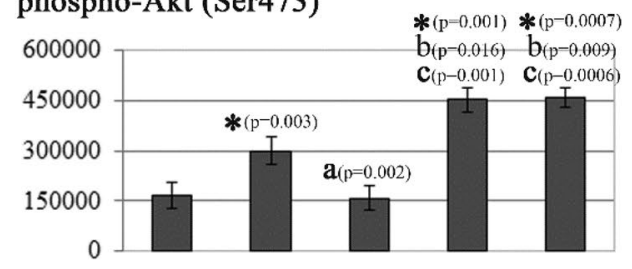


PARP-1

Fra-1

$(42 \mathrm{kDa}) \longrightarrow$

Fra-2

$(40 \mathrm{kDa})$

\section{c-Fos}

(62 kDa)
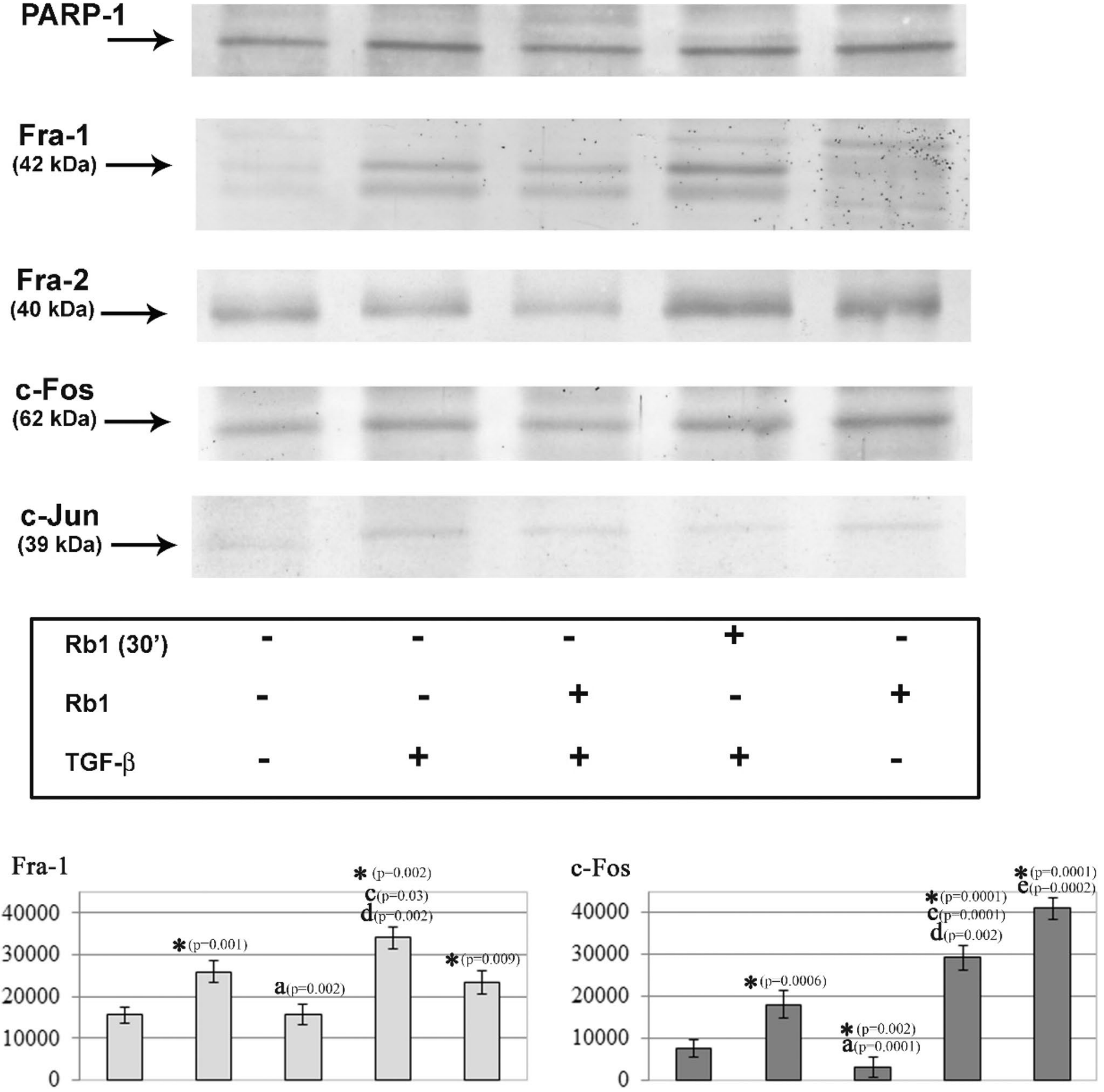

Fra-2

c-Jun
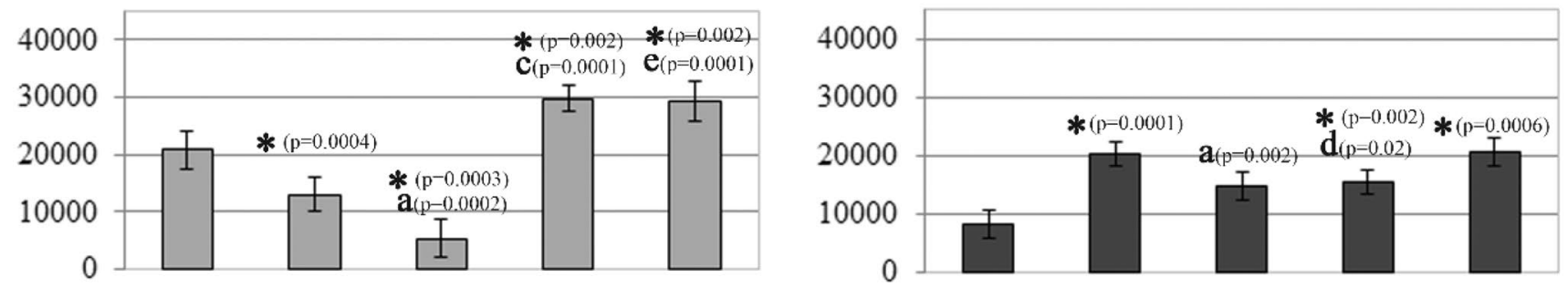
4Fig. 4 Representative western blots showing the expressions of Fra1, Fra-2, c-Jun and c-Fos in neutrophils. Neutrophils were treated with TGF- $\beta(10 \mathrm{ng} / \mathrm{ml})$ or with/without Rb1 $(50 \mu \mathrm{g} / \mathrm{ml})$. The nuclear fractions obtained from those cells were used to detect for Fra-1, Fra-2, c-Jun and c-Fos protein levels by Western blot analyses. Band intensity was quantified using ImageJ software and expressed in arbitrary units (A.U.). Data shown are mean $( \pm$ SE) of five independent experiments. Value significantly different between $*$ unstimulated and stimulated cells $(\mathrm{p}<0.05)$; a cells incubated only with TGF- $\beta$ and cells incubated with TGF- $\beta$ and Rb1 $(\mathrm{p}<0.05)$; $\mathbf{c}$ stimulated cells and incubated with TGF- $\beta$ and Rb1 ( $<<0.05)$; d cells incubated only with Rb1 and cells incubated with Rb1 (30') and TGF- $\beta$ ( $p<0.05$ ); e cells incubated only with Rb1 and cells incubated only with TGF- $\beta$ $(\mathrm{p}<0.05)$

data may explain the simultaneous increase in phosphorylation of p38 and expression of transcription factors (c-Jun, c-Fos and Fra-1) in TGF- $\beta$-stimulated neutrophils.

Our study also tried to answer question whether demonstrated effect of TGF- $\beta$ on human neutrophils inducing APRIL expression in these cells, as well as the demonstrated TGF- $\beta$ signaling pathway, can be regulated by the action of ginsenoside $\mathrm{Rb} 1$.

The results of this study showed for the first time that $\mathrm{Rb} 1$ decreases the expression of APRIL as well as that of all the signaling proteins in TGF- $\beta$-stimulated cells, which indicates that this ginsenoside may modulate the signal activated by these cytokines before the integration of the signal from receptors and tyrosine cytoplasmic kinases, which, with the participation of Ras protein, is then transmitted to the MAP kinase cascade.

Furthermore, our laboratory study with Rb1 showed that this compound does not induce the expression of APRIL and level p38 kinase, whereas it contributes to an increased activation of the PI3K/Akt pathway and all the transcription factors studied.

A similar direction of changes was observed in the cells first treated with Rb1 and then stimulated with TGF- $\beta$. Based on the changes observed in the expression of the proteins studied, it can be finally assumed that $\mathrm{Rb} 1$ prevents the activation of the signal pathway induced by TGF- $\beta$.

The changes in the activity of the PI3K/Akt pathway in neutrophils observed in our study as a result of $\mathrm{Rb} 1$ activity may result from the structure of ginsenoside. This compound is classified among phytoestrogens, which are polyphenol nonsteroidal plant compounds with similar biological activity as estrogens (Kang and Min 2012; Xin et al. 2019). The biological action of estrogen is carried out by two different intracellular receptors, the estrogen receptor (ER) $\alpha$ and the ER $\beta$, which are encoded by different genes (DeMayo et al. 2002; Yaşar et al. 2017). It has been shown that there is a direct interaction between ER $\alpha$ and the PI3K pathway that defines the physiological nonnuclear signaling pathway of action of estrogen (Simoncini 2000). According to the reports of other authors, Rb1 augments the cellular antioxidant defenses through ER-dependent HO-1 induction via the G $\beta 1 /$ PI3K/Akt-Nrf2 signaling pathway, thereby protecting cells from oxidative stress (Hwang and Jeong 2010).

Similar observations were made by other researchers, including Lan et al. (2011), Jeong et al. (2014), and Wang et al. (2008), who concluded that the compound Rb1 exerts a protective effect on the cells by activating the PI3K/AKT pathway.

The results observed regarding the level of Akt phosphorylation with the use of TGF- $\beta$ and Rb1 in different combinations suggest that these stimulators have a mutually additive effect.

In our research model, the different activities of the effector proteins, which were observed depending on the activation status of neutrophils, indicated a dual mechanism of action of Rb1. In addition, there are data indicating the pro- and anti-inflammatory characteristics of Rb1. In their research on macrophages, Liou et al. (2006) showed that Rb1 may contribute to intensifying the production of inflammatory cytokines. In contrast, Park et al. (2012) demonstrated that $\mathrm{Rb} 1$ led to a decrease in cytokine production in BV2 microglial cells and primary cultured microglia stimulated with LPS.

In summary, the study shows that in human neutrophils TGF- $\beta$ activates the Akt and p38 kinases, and the transcription factors c-Jun, c-Fos and Fra-1, which may be involved in the regulation of APRIL synthesis. However, the Rb1 ginsenoside reduces the effect of TGF- $\beta$ on APRIL production by resolving the cytokine signaling pathway. Ginsenoside $\mathrm{Rb} 1$ appears to be a favorable factor that may be potentially used in the modulation of tumor-promoting APRIL expression.

Acknowledgements The authors thank Mrs Malgorzata Walko-Lachowicz for expert technical assistance.

Author Contributions WRW conducted the statistical analyses and wrote the manuscript with critical comments and input from EJ, MG, KN, NWK and AK; WRW, NWK, MG, AK and EJ designed the research plan; WRW, NWK, EJ and MG conducted the original study and follow-up study from which the data were generated. All authors read and approved the final manuscript.

Funding This work was supported by the Medical University of Bialystok, Poland, (Project no: 143-06801F).

Data Availability The datasets used and/or analyzed during the current study are available from the corresponding author on reasonable request.

\section{Compliance with Ethical Standards}

Conflict of Interest The authors declare that they have no known competing financial interests or personal relationships that could have appeared to influence the work reported in paper. 
Ethical Approval The Ethics Committee of the Medical University of Bialystok (R-I-002/106/2015) approved this study.

Informed Consent All study participants provided full informed consent prior to participation.

Open Access This article is licensed under a Creative Commons Attribution 4.0 International License, which permits use, sharing, adaptation, distribution and reproduction in any medium or format, as long as you give appropriate credit to the original author(s) and the source, provide a link to the Creative Commons licence, and indicate if changes were made. The images or other third party material in this article are included in the article's Creative Commons licence, unless indicated otherwise in a credit line to the material. If material is not included in the article's Creative Commons licence and your intended use is not permitted by statutory regulation or exceeds the permitted use, you will need to obtain permission directly from the copyright holder. To view a copy of this licence, visit http://creativecommons.org/licenses/by/4.0/.

\section{References}

Andzinski L, Wu CF, Lienenklaus S et al (2015) Delayed apoptosis of tumor associated neutrophils in the absence of endogenous IFNbeta. Int J Cancer 136:572-583

Attisano L, Wrana JL (2002) Signal transduction by the TGF-beta superfamily. Science 296:1646-1647

Bat-Erdene U, Quan E, Chan K et al (2018) Neutrophil TLR4 and PKR are targets of breast cancer cell glycosaminoglycans and effectors of glycosaminoglycan-induced APRIL secretion. Oncogenesis $7: 45$

Brandes ME, Mai UE, Ohura K et al (1991) Type I transforming growth factor-beta receptors on neutrophils mediate chemotaxis to transforming growth factor-beta. J Immunol 147:1600-1606

Cantelli G, Crosas-Molist E, Georgouli M et al (2017) TGF $\beta$-induced transcription in cancer. Semin Cancer Biol 42:60-69

Chen C, Zhang H, Xu H et al (2019) Ginsenoside Rb1 ameliorates cisplatin-induced learning and memory impairments. J Ginseng Res 43:499-507

Cho J, Park W, Lee S et al (2004) Ginsenoside-Rb1 from Panax ginseng C.A. Meyer activates estrogen receptor-alpha and -beta, independent of ligand binding. J Clin Endocrinol Metab 89:3510-3515

Coffelt SB, Wellenstein MD, de Visser KE (2016) Neutrophils in cancer: neutral no more. Nat Rev Cancer 16:431-446

de Caestecker M (2004) The transforming growth factor-beta superfamily of receptors. Cytokine Growth Factor Rev 15:1-11

DeMayo FJ, Zhao B, Takamoto N et al (2002) Mechanisms of action of estrogen and progesterone. Ann NY Acad Sci 955:48-59

Derynck R, Zhang YE (2003) Smad-dependent and Smad-independent pathways in TGF-beta family signalling. Nature 425:577-583

Dillon SR, Gross JA, Ansell SM et al (2006) An APRIL to remember: novel TNF ligands as therapeutic targets. Nat Rev Drug Discov 5:235-246

Fridlender ZG, Albelda SM (2012) Tumor-associated neutrophils: friend or foe? Carcinogenesis 33:949-955

Fridlender ZG, Sun J, Kim S et al (2009) Polarization of tumor-associated neutrophil phenotype by TGFbeta: "N1" versus "N2" TAN. Cancer Cell 16:183-194

Granot Z, Fridlender ZG (2015) Plasticity beyond cancer cells and the "immunosuppressive switch". Cancer Res 75:4441-4415

Guan L, Li W, Liu Z (2002) Effect of ginsenoside-Rb1 on cardiomyocyte apoptosis after ischemia and reperfusion in rats. J Huazhong Univ Sci Technolog Med Sci 22:212-215
Hahne M, Kataoka T, Schröter M et al (1998) APRIL, a new ligand of the tumor necrosis factor family, stimulates tumor cell growth. J Exp Med 188:1185-1190

Hanada M, Feng J, Hemmings BA (2004) Structure, regulation and function of PKB/AKT: a major therapeutic target. Biochim Biophys Acta 1697:3-16

Hawkins PT, Stephens LR, Suire S et al (2010) PI3K signaling in neutrophils. Curr Top Microbiol Immunol 346:183-202

He B, Chadburn A, Jou E et al (2004) Lymphoma B cells evade apoptosis through the TNF family members BAFF/BLyS and APRIL. J Immunol 172:3268-3279

Hwang YP, Jeong HG (2010) Ginsenoside Rb1 protects against 6-hydroxydopamine-induced oxidative stress by increasing heme oxygenase-1 expression through an estrogen receptor-related $\mathrm{PI} 3 \mathrm{~K} / \mathrm{Akt} / \mathrm{Nrf2}$-dependent pathway in human dopaminergic cells. Toxicol Appl Pharmacol 242:18-28

Jang JS, Kim JH, Seo GY et al (2011) TGF- $\beta 1$ stimulates mouse macrophages to express APRIL through Smad and p38MAPK/CREB pathways. Mol Cells 32:251-255

Jeong JJ, Kim B, Kim DH (2014) Ginsenoside Rb1 eliminates HIV-1 (D3)-transduced cytoprotective human macrophages by inhibiting the AKT pathway. J Med Food 17:849-854

Kang S, Min H (2012) Ginseng, the 'Immunity Boost': the effects of Panax ginseng on immune system. J Ginseng Res 36:354-368

Kang X, Hong W, Xie K et al (2019) Ginsenoside Rb1 pretreatment reverses hippocampal changes in BDNF/TrkB mRNA and protein in rats subjected to acute immobilization stress. Drug Des Devel Ther 13:2127-2134

Karin M (1995) The regulation of AP-1 activity by mitogen-activated protein kinases. J Biol Chem 270:16483-16486

Kenarova B, Neychev H, Hadjiivanova C et al (1990) Immunomodulating activity of ginsenoside Rg1 from Panax ginseng. Jpn J Pharmacol 54:447-454

Keshavan S, Calligari P, Stella L et al (2019) Nano-bio interactions: a neutrophil-centric view. Cell Death Dis 10:569

Keski-Oja J, Koli K, von Melchner H (2004) TGF-beta acti-vation by traction? Trends Cell Biol 14:657-659

Kobayashi Y (2015) Neutrophil biology: an update. EXCLI J 14:220-227

Lan TH, Xu ZW, Wang Z et al (2011) Ginsenoside Rb1 prevents homocysteine-induced endothelial dysfunction via PI3K/Akt activation and PKC inhibition. Biochem Pharmacol 82:148-155

Lee KA, Kim KT, Chang PS et al (2014) In vitro cytotoxic activity of ginseng leaf/stem extracts obtained by subcritical water extraction. J Ginseng Res 38:289-292

Li DW, Zhou FZ, Sun XC et al (2019) Ginsenoside Rb1 protects dopaminergic neurons from inflammatory injury induced by intranigral lipopolysaccharide injection. Neural Regen Res 14:1814-1822

Liou CJ, Huang WC, Tseng J (2006) Short-term oral administration of ginseng extract induces type- 1 cytokine production. Immunopharmacol Immunotoxicol 28:227-240

Mehra A, Wrana JL (2002) TGF-beta and the Smad signal transduction pathway. Biochem Cell Biol 80:605-622

Mhawech-Fauceglia P, Kaya G, Sauter G et al (2006) (2006) The source of APRIL up-regulation in human solid tumor lesions. J Leukoc Biol 80:697-704

Miyazawa K, Shinozaki M, Hara T et al (2002) Two major Smad pathways in TGF-beta superfamily signalling. Genes Cells 7:1191-1216

Moreaux J, Veyrune JL, De Vos J et al (2009) APRIL is overexpressed in cancer: link with tumor progression. BMC Cancer 9:83

Okkenhaug K (2013) Signaling by the phosphoinositide 3-kinase family in immune cells. Annu Rev Immunol 31:675-704

Park EK, Shin YW, Lee HU et al (2005) Inhibitory effect of ginsenoside $\mathrm{Rb} 1$ and compound $\mathrm{K}$ on $\mathrm{NO}$ and prostaglandin $\mathrm{E} 2$ 
biosyntheses of RAW264.7 cells induced by lipopolysaccharide. Biol Pharm Bull 28:652-656

Park JS, Shin JA, Jung JS et al (2012) Anti-inflammatory mechanism of compound $\mathrm{K}$ in activated microglia and its neuroprotective effect on experimental stroke in mice. J Pharmacol Exp Ther 341:59-67

Pillay J, den Braber I, Vrisekoop N et al (2010) In vivo labeling with $2 \mathrm{H} 2 \mathrm{O}$ reveals a human eutrophil lifespan of 5.4 days. Blood 116:625-627

Reddy SP, Mossman BT (2002) Role and regulation of activator protein-1 in toxicant-induced responses of the lung. Am J Physiol Lung Cell Mol Physiol 283:L1161-1178

Rosales C (2018) Neutrophil: a cell with many roles in inflammation or several cell types? Front Physiol 20:113

Scaglione F, Ferrara F, Dugnani S et al (1990) Immunomodulatory effects of two extracts of Panax ginseng CA. Meyer Drugs Exp Clin Res 16:537-542

See DM, Broumand N, Sahl L et al (1997) In vitro effects of echinacea and ginseng on natural killer and antibody-dependent cell cytotoxicity in healthy subjects and chronic fatigue syndrome or acquired immunodeficiency syndrome patients. Immunopharmacology 35:229-235

Shaul ME, Levy L, Sun J et al (2016) Tumor-associated neutrophils display a distinct N1 profile following TGF $\beta$ modulation: a transcriptomics analysis of pro- vs antitumor TANs. Oncoimmunology $5: \mathrm{e} 1232221$

Shaulian E, Karin M (2002) AP-1 as a regulator of cell life and death. Nat Cell Biol 4:E131-136

Shen L, Smith JM, Shen Z et al (2007) Inhibition of human neutrophil degranulation by transforming growth factor- $\beta 1$. Clin Exp Immunol 149:155-161

Shi Y, Massague J (2003) Mechanisms of TGF-beta signaling from cell membrane to the nucleus. Cell 113:685-700

Simoncini T, Hafezi-Moghadam A, Brazil DP et al (2000) Interaction of estrogen receptor with the regulatory subunit of phosphatidylinositol-3-OH kinase. Nature 407:538-541

Sionov RV, Fridlender ZG, Granot Z (2015) The multifaceted roles neutrophils play in the tumor microenvironment. Cancer Microenviron 8:125-158

Skopinska-Rozewska E (2009) Immunotropic and anti-tumor effects of plant adaptogens. I Panax ginseng. Centr Eur J Immunol 34:207-211

Sun K, Wang CS, Guo J et al (2007) Protective effects of ginsenoside $\mathrm{Rb}$, ginsenoside $\mathrm{Rg} 1$, and notoginsenoside R1 on lipopolysaccharide-induced microcirculatory disturbance in rat mesentery. Life Sci 81:509-518

Tian M, Schiemann WP (2009) The TGF- $\beta$ paradox in human cancer: an update. Future Oncol 5:259-271

Travis MA, Sheppard D (2014) TGF- $\beta$ activation and function in immunity. Annu Rev Immunol 32:51-82

Treffers LW, Hiemstra IH, Kuijpers TW et al (2016) Neutrophils in cancer. Immunol Rev 273:312-328
Vincent FB, Northcott M, Hoi A et al (2013a) Association of serum $B$ cell activating factor from the tumor necrosis factor family (BAFF) and a proliferation-inducing ligand (APRIL) with central nervous system and renal disease in systemic lupus erythematosus. Lupus 22:873-884

Vincent FB, Saulep-Easton D, Figgett WA et al (2013b) The BAFF/ APRIL system: emerging functions beyond $\mathrm{B}$ cell biology and autoimmunity. Cytokine Growth Factor Rev 24:203-215

Wang Z, Li M, Wu WK et al (2008) Ginsenoside Rb1 preconditioning protects against myocardial infarction after regional ischemia and reperfusion by activation of phosphatidylinositol-3-kinase signal transduction. Cardiovasc Drugs Ther 22:443-452

Wang N, Wan JB, Chan SW et al (2011) Comparative study on saponin fractions from Panax notoginseng inhibiting inflammationinduced endothelial adhesion molecule expression and monocyte adhesion. Chin Med 13:37

Wang X, Qiu L, Li Z et al (2018) Understanding the multifaceted role of neutrophils in cancer and autoimmune diseases. Front Immunol 9:2456

Wollacott AM, Robinson LN, Ramakrishnan B et al (2019) Structural prediction of antibody-APRIL complexes by computational docking constrained by antigen saturation mutagenesis library data. $\mathrm{J}$ Mol Recognit 32:e2778

Wrana JL (2019) Signaling by the TGF $\beta$ superfamily. Cold Sprong Harbor Lab Press 28:1-3

Xin C, Quan H, Kim JM et al (2019) Ginsenoside Rb1 increases macrophage phagocytosis through p38 mitogen-activated protein kinase/Akt pathway. J Ginseng Res 43:394-401

Yang L, Pang Y, Moses HL (2010) TGF- $\beta$ and immune cells: an important regulatory axis in the tumor microenvironment and progression. Trends Immunol 31:220-227

Yaşar P, Ayaz G, User SD et al (2017) Molecular mechanism of estrogen-estrogen receptor signaling. Reprod Med Biol 16:4-20

Youn JI, Gabrilovich DI (2013) New roles of Rb1 in expansion of MDSCs in cancer. Cell Cycle 12:1329-1330

Zhang Q, Yu N, Lee C (2014) Mysteries of TGF- $\beta$ Paradox in benign and malignant cells. Front Oncol 4:94-99

Zhu HJ, Burgess AW (2001) Regulation of transforming growth factorbeta signaling. Mol Cell Biol Res Commun 4:321-330

Zhuang CL, Mao XY, Liu S et al (2014) Ginsenoside Rb1 improves postoperative fatigue syndrome by reducing skeletal muscle oxidative stress through activation of the PI3K/Akt/Nrf2 pathway in aged rats. Eur J Pharmacol 740:480-487

Publisher's Note Springer Nature remains neutral with regard to jurisdictional claims in published maps and institutional affiliations. 